\title{
Improvement of TiN nanoparticles EPD inducing steric stabilization in non-aqueous suspensions
}

\author{
C. Mendoza ${ }^{a}$, Z. González ${ }^{a}$, Y. Castro ${ }^{\mathrm{a}, *}$, E. Gordo $^{\mathrm{b}}$, B. Ferrari ${ }^{\mathrm{a}}$ \\ a Instituto de Cerámica y Vidrio, CSIC, c/Kelsen 5, 28049 Madrid, Spain

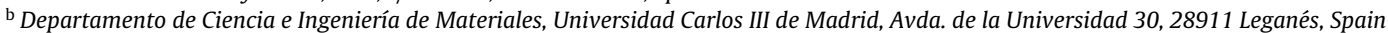

\section{A R T I C L E I N F O}

\section{Article history:}

Received 24 March 2015

Received in revised form 27 May 2015

Accepted 20 June 2015

Available online 3 July 2015

\section{Keywords:}

TiN

Coatings

Colloidal

Polyethylenimine

Electrophoretic deposition

\begin{abstract}
A B S T R A C T
In this work, the process parameters involved in the electrophoretic deposition (EPD) to obtain thin TiN films was studied and optimised. The stability of commercial TiN nanopowder in isopropyl alcohol adding a cationic polymer (polyethylenimine) as dispersant, with different molecular weights, was investigated to determine the kinetics of the deposition and to reach the most efficient EPD process. Cathodic EPD was performed over electro-polished stainless steel substrates. It was found that the provided dispersion when the PEI with the highest molecular weight was added to the suspension, leads to the best deposition behaviour for short times. New flocculation phenomena were described which affect to the sticking factor, and thus to the evolution of the EPD kinetics. As a result of the designed stabilization system, a reliable and versatile EPD method to produce well consolidated nano-TiN coatings at $1200^{\circ} \mathrm{C}$ in vacuum atmosphere was described.
\end{abstract}

(c) 2015 Elsevier Ltd. All rights reserved.

\section{Introduction}

The exceptional hardness of non-oxide materials is a reflection of the strong bonding forces between the components of their atomic lattice. This is the reason why this material group has high melting temperatures, small thermal expansion coefficients and high elastic moduli. Metal carbides and nitrides present good resistance against corrosion, and very high cohesive strength and hardness, associated with their extremely high melting points. These properties associated with their chemical characteristics make them an alternative to noble metals in catalysis [1,2], and to metal oxides under harsh conditions $[3,4]$. Among non-oxide ceramics, titanium carbides ( $\mathrm{TiC}$ ) and titanium nitrides (TiN) have been specially considered a promise hard material with excellent properties such as high thermal and electrical conductivity and good wear resistance, so it has been regularly deposited on bulk iron based materials to improve the surface features. Although TiN will oxidize at $800^{\circ} \mathrm{C}$ in air, it is chemically stable at room temperature. Moreover, TiN has excellent infrared reflectivity properties, reflecting in a spectrum similar to elemental gold, which gives it a yellowish color. Due to these properties, TiN has been used for a long time in the processing of hard coatings and cutting tools, as other metal carbides and nitrides (TiN, ZrN, CrN, WC) [5]. In fact,

\footnotetext{
* Corresponding author.

E-mail address: castro@icv.csic.es (Y. Castro).
}

surface coatings are the most relevant applications of those materials, i.e., improving hardness and wear resistance even in surgical tools and implants [6].

Thin films of the transition metal nitrides are commonly prepared by nitridation, chemical (CVD) or physical vapor deposition (PVD). Chemical methods are applied in cases where the substrates are more stable with the temperature, such as in the cemented tool industry and for tribological parts such as bearings, valves and nozzles. On the other hand, physical methods allow the deposition of thin films at lower temperatures than CVD, which is an advantage when the coated substrate is susceptible. For example, the deposition of wear resistant coatings onto high speed cutting tools is less suited to CVD because of the low austenitising temperature $\left(450-550^{\circ} \mathrm{C}\right)$ of steel. TiN coatings have been processed by CVD and PVD [7], by methods such as cathodic arc evaporation [8], electron beam deposition [9], plasma [10], etc. Up to our knowledge the TiN films prepared by those techniques hardly reach 3-5 $\mu \mathrm{m}$ in thickness [3], exhibiting large crystallites sizes, for example $100 \mathrm{~nm}$ from films prepared by low voltage-high current PVD, $60 \mathrm{~nm}$ from plasma enhanced magnetron PVD, $200 \mathrm{~nm}$ from cathodic arc PVD and $500 \mathrm{~nm}$ from high temperature CVD [7]. In this sense, a number of techniques, i.e., electrodeposition or sol-gel, have been also considered with the objective to design a new method of synthesis and deposition of TiN nanoparticles at low temperature $[11,12,13]$.

Electrophoretic deposition (EPD) is a colloidal processing method which consists in the electrically driven movement and deposition of charged particles onto a conducting substrate. Under- 
standing the colloidal behavior of nanoparticles is therefore a key point in order to prepare stable and disperse suspensions suitable for EPD [14]. This technique has received increasing attention because of simplicity, low cost, versatility, possibility of using complex shapes and capability of scaling-up. EPD comprises two steps: (i) charged colloidal suspended particles migrate towards an electrode under an applied electric field and (ii) particles deposit onto an oppositely charged substrate forming a dense layer. The EPD is able to produce dense ceramic coatings, reproducing the substrate shape, which thickness mainly depends on the size of the particle to deposit, but also stability and dispersing conditions of the suspension. The most general equation [15] formulated up today to calculate the deposition rate is:

$m(t)=m_{0}\left(1-e^{-t / \tau}\right)$

where $m(\mathrm{~g})$, is the deposition mass, $m_{0}(\mathrm{~g})$, is the initial amount of powder in suspension and $\tau(\mathrm{s})$ is the characteristic time, calculated by:

$\tau=\frac{V}{f S E \mu_{e}}$

where $V\left(\mathrm{~cm}^{3}\right)$, is the volume of suspension, $S\left(\mathrm{~cm}^{2}\right)$, is the conducting area, $E\left(\mathrm{~V} \mathrm{~cm}^{-1}\right)$, is the applied electric field, $\mu_{\mathrm{e}},\left(\mathrm{m}^{2} \mathrm{~V}^{-1} \mathrm{~s}^{-1}\right)$, is the electrophoretic mobility of the nanoparticles, and $f(0<f<1)$, is the sticking factor. The sticking factor represents the percentage of depositing particles among the arriving particles to the work electrode by electrophoresis.

Up today models proposed for EPD kinetics have been formulated considering the electrophoresis process. However, the effect of some parameters that could affect to the kinetics, such as the deposition feature or the coating morphology, has not been extensively considered. These effects have been only quantified throughout the sticking factor, $f$ (Eq. (2)). Some of these effects have been described in the literature during the last decade, regarding phenomena that take place at: (1) the surface of the substrate, (2) the suspension itself, (3) the interface substrate-suspension and (4) the film growing.

Today we know that physical phenomena have a relevant role in EPD. Most of the time, the geometric surface of the working electrode or substrate is considered, neglecting the surface of conduction or the cumulative charge effect in edges and peaks. So, the characteristics of the substrate surface, such as its nature [16], roughness, surface charge [17] or its electrical response [18,19], determine not only the morphology of the films and even the success of the assembly process, but also the process kinetics.

At the suspension, phenomena associated to the electrophoresis, such as the solvent warming or the solvent electroosmosis, promote changes in both suspension and electric conditions when the process is running. Current passing through the system increases the suspension temperature, raising dielectric constants and lowering viscosities of the solvent, thus promoting a faster deposition rate. Contrarily, the whole suspension (solvent and charged species) acts as a semiconductor and consequently the suspension conductivity increases with the temperature leading to a fall of yield deposition.

Other source of divergences between experimental and theoretical results is the particle aging and re-agglomeration, also as a consequence of the suspension warming or the disregarded particles stabilization [20]. In this sense, during the last five years, special attention is paid in the effect on deposition of different mechanisms that can be used to stabilize the suspensions. The use of particular solvents [21], their acid/basic character [22-24] or the stabilizers [25-29] added to the suspensions have been studied as key-parameters not only to promote the electrophoresis but also to successfully control deposition. For example, the electro-hydrodynamic of the liquid at the electrode surroundings determines not only the array ordering of nano-platelets [30,31], but also the specific adsorption of the stabilizer agent on the particle surface could drive the packing of nanoplates [30]. However, no other mechanism of flocculation, apart from increase of $\mathrm{pH}$ in the vicinity of the cathode surface as a consequence of the water hydrolysis [32,33] has been proposed. The mechanisms which promote the flocculation of particles on the electrode surface are key phenomena to determine the particles adhesion to the substrate as well as the cohesion of the deposit. These mechanisms determine the nano-entities assembly and the rate of the film growth, so they finally predict the EPD success.

In this work, the standardization of the EPD of TiN nanopowders will allow to compare the kinetics results on the base of the stabilization of the nanoparticles with cationic dispersants, such as polyethilenimine (PEI) with two different molecular weights, and to propose a novel stabilization mechanism that explain the EPD kinetics and provides enough compatibility to obtain a successfully coating on different substrates.

\section{Materials and methods}

\subsection{Characterization and stabilization of TiN nanopowders}

As-received commercial TiN nanopowder (Hefei Kaier Nanometer Energy \& Technology, China) was characterized by helium pycnometry (Multipycnometer, Quantachrome Co., USA) to determine its density $(\rho)$ and by Physisorption Analyzer (ASAP 2020, Micromeritics, USA) to measure the specific surface area and micromesoporosity. The particle size and morphology were examined by field emission scanning electron microscopy (FE-SEM) using S-4700 microscope (Hitachi, Japan). Crystalline phases was characterized by X-Ray Diffraction (XRD) (D8 Advance, Bruker, Germany), using $\mathrm{CuK} \alpha$ radiation. The thermogravimetric and differential thermal analysis (TG-DTA) were carried out in air, with a constant heating rate of $3^{\circ} \mathrm{C} / \mathrm{min}$ up to temperatures of $1000^{\circ} \mathrm{C}$, in TG-DTA equipment (PerkinElmer, USA). Dynamic sintering test was performed in $\mathrm{N}_{2}$ atmosphere using a TiN slice obtained by pressing of the nanopowder. A push-rod dilatometer (Netzsch, Germany) was used under flowing atmosphere of $\mathrm{N}_{2}$ to avoid the oxidation of the nanoparticles. This test was recorded at temperatures up to $1400^{\circ} \mathrm{C}$ at a heating rate of $5^{\circ} \mathrm{C} / \mathrm{min}$.

TiN suspensions $\left(0.1 \mathrm{~g} \mathrm{~L}^{-1}\right)$ were prepared using isopropyl alcohol (99.7\%, Panreac, Spain) as solvent and polyethilenimine (PEI, Sigma-Aldrich, Germany) as stabilizer. For comparative proposes, two PEI with molecular weights of 2000 and $25,000 \mathrm{~g} \mathrm{~mol}^{-1}$ (PEI2,000 and PEI-25,000, respectively) were added, while hydrazine monohydrate (64-65\%, Sigma-Aldrich, Germany) was used to modify the basicity of the solvent. The dispersion and stability of TiN suspensions was evaluated as a function of zeta potential. This parameter was determined by laser Doppler velocimetry using a Zetasizer Nano ZS (Malvern S, UK). Mechanical stirring and sonication (Ultrasonication Probe, UP 400S, Hielscher, Germany) were used as dispersing methods to break the soft agglomerates.

\subsection{EPD process}

TiN films were shaped from TiN highly stabilized suspensions $\left(1 \mathrm{~g} \mathrm{~L}^{-1}\right)$ by EPD on as-received stainless steel foils (AISI 316L and AISI 304 ) of $30 \times 20 \times 0.5 \mathrm{~mm}$ and on titanium cylinders of $15 \mathrm{~mm}$ of diameter and $0.5 \mathrm{~mm}$ of highness fabricated by uniaxial pressing, pre-cleaning using an industrial protocol. The counter electrode was a platinum foil of similar dimensions than stainless steel substrates, separated from the work electrode by a distance of $2 \mathrm{~cm}$ in the electrophoretic cell. EPD was performed under galvanostatic/potenciostatic conditions using a high voltage power source 

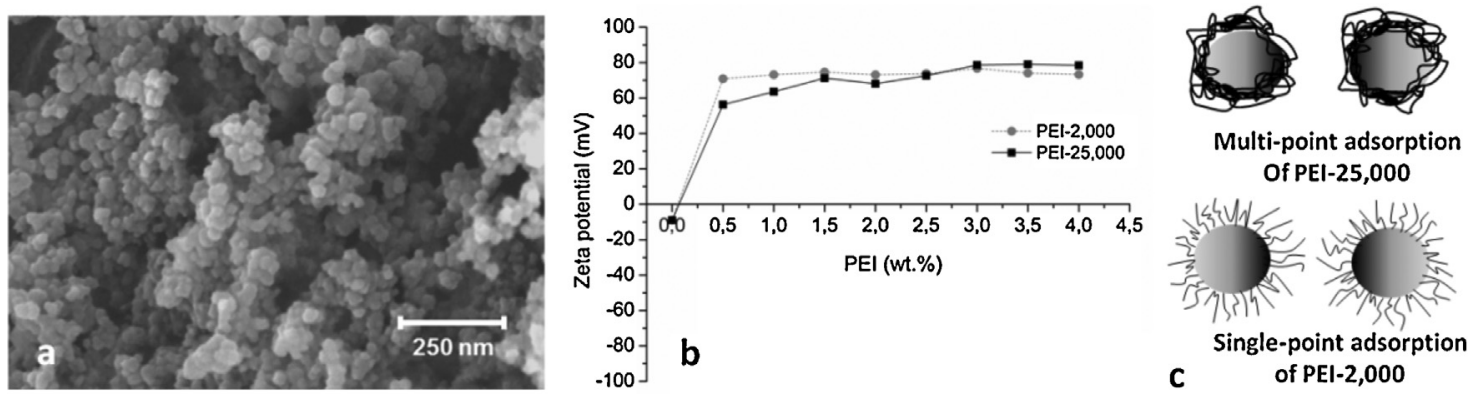

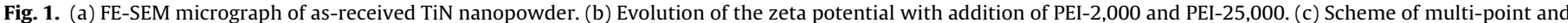
single-point adsorption of PEI.

(2611 System SourceMeter, Keithley Instruments Inc., USA), applying voltages $<90 \mathrm{~V}$, current densities $<0.2 \mathrm{~mA} \mathrm{~cm}^{-2}$ and deposition times from 1 to $80 \mathrm{~min}$. After EPD, green coatings were left to dry at room conditions. Samples were thermally treated in vacuum atmosphere at $1200^{\circ} \mathrm{C}$ for $1 \mathrm{~h}$ with heating and cooling rates of $5^{\circ} \mathrm{C} \mathrm{min}^{-1}$.

\subsection{Characterization of the coatings}

The homogeneity at nanoscale of the coatings produced by EPD was determined by atomic force microscopy (AFM) on a Cervantes AFM System (Nanotec Electronica, S.L., Spain) operating in noncontact dynamic mode with amplitude modulation. Silicon nitride tips with a radius lower than $7 \mathrm{~nm}$ were used. The tips have a resonance frequency near to $330 \mathrm{kHz}$ and a force constant in the range of 42 $\mathrm{N} \mathrm{m}^{-1}$. All AFM images were taken in air at room temperature. The AFM piezoelectric scanner allows a maximum sample XY scan of $10 \times 10 \mu \mathrm{m}^{2}$. In order to obtain representative information from the film surfaces, at least three separate areas of each film were measured; dynamic mode parameters were managed for a better resolution avoiding lateral effects of tip-sample interactions.

Microstructural observations, thickness and roughness measurements were made by FE-SEM, using a S-4700 microscope (Hitachi, Japan) and by profilometer using a Surtronic 3+ instrument (Taylor Hobson), respectively.

\section{Results and discussions}

\subsection{EPD of steric stabilized nano-TiN suspensions}

Agglomerates of $\sim 200 \mathrm{~nm}$ formed by nanoparticles of $26-32 \mathrm{~nm}$ can be observed on the FE-SEM micrography of TiN powders in Fig. 1a. Stabilization of TiN suspensions $\left(0.1 \mathrm{~g} \mathrm{~L}^{-1}\right)$ was reached adding PEI with different molecular weight (2000 and $25,000 \mathrm{~g} \mathrm{~mol}^{-1}$ ) through the modification of the surface charge of the particles. Zeta potential gives information of the adsorption of the polymer onto the particle surface, its ionization state and eventually about further interaction between particles. The plot in Fig. 1b shows the evolution of the zeta potential of TiN suspensions with the amount of PEI (wt.\%). TiN particles dispersed in isopropanol showed a negative zeta potential of $-10 \mathrm{mV}$ evidencing the acidic character of the powder related to the solvent [34]. The manipulation, as well as the preparation of the suspensions, was done at room conditions, and consequently a thin layer of titanium oxide should cover the TiN nanoparticles. It has been reported elsewhere $[35,36]$ that the passivation layer surrounding Ti-based particles slightly displace the isoelectric point of those powders. For comparative proposes, in our study, both PEIs were added to suspensions prepared under similar conditions. So, TiN particles had a similar surface chemistry in both suspensions.
Whatever was the molecular weight, the addition and adsorption of PEI leads to positive zeta potentials, providing in all cases an electro-steric mechanism of stability. In fact, the TiN suspension in isopropanol had $\mathrm{pH} 4$, and consequently both PEI molecules were ionized and positively charged when they have been added to the suspension [37]. The dissimilitude between the charge of the particles and the PEI chains promotes their electrostatic attraction and further adsorption of the polymers onto the surface of the particle. Generally, the amine groups of the PEI chains can anchor to the TiN surface in different ways, by Wan der Waals attraction, but also throughout quelate and dative bonds. However, differences in molecular weight of PEI chains will determine their adsorption.

When the PEI-25,000 addition increases, the measured zeta potential values exhibit a more relevant contribution of the electrostatic effect to the electro-steric mechanism. Zeta potential ranges from $+55 \mathrm{mV}$ for the $0.5 \mathrm{wt}$.\% to $+75 \mathrm{mV}$ for the $4.0 \mathrm{wt}$.\% addition of PEI-25,000. For further additions, the PEI-25,000 does not longer adsorb. However for PEI-2,000, the addition of $0.5 \mathrm{wt} . \%$ leads to a maximum zeta potential of $+70 \mathrm{mV}$ which is maintained after further additions. Consequently, a larger addition than $0.5 \mathrm{wt}$ \% of PEI-2,000 will promote the presence of free-chains in the suspension. Differences in the surface charge between both particle-stabilizer systems can be attributed to the related adsorption of PEI-2,000 and PEI-25,000 onto the TiN surface in different ways. For the addition of 1.5 wt.\% of PEI-2,000 the surface of TiN is completely covered, while the addition of a similar amount in weight of PEI-25,000 leads to free sites in the TiN surfaces. In this sense, changes in the ionization state of PEI-25,000 could conduct to a multi-points anchoring of the long chain to the surface of the nanoparticles. Fig. 1c shows a scheme illustrating the single-point and multi-point adsorption of PEI chains.

The TiN coatings were shaped on the stainless steel by EPD

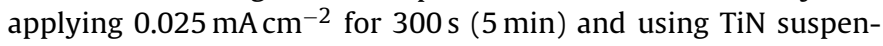
sions with 1.5 wt.\% of PEI-2,000 and PEI-25,000 with similar zeta potential $(+70 \mathrm{mV})$. As-received polished stainless steel foils (AISI 316) were used as substrate to study EPD kinetics after a standard cleaning treatment. Fig. 2a shows the variation of the zeta potential and the deposited mass by EPD as a function of concentration of hydrazine (related to the solid content). The addition of a reducing agent as hydrazine modifies the acid/basic character of the solvent and then the ionization state of PEI chains adsorbed on the surface of the nanoparticles. The $\mathrm{pH}$ values change from 4 ( $0 \mathrm{wt} . \%$ of hydrazine) to 8 ( $1.5 \mathrm{wt}$.\% of hydrazine) and thus PEI chains deprotonate. A similar behaviour of the zeta potential was observed for both suspensions, evidencing the reduction of the electrostatic component of the electro-steric mechanism of stabilization provided by the PEI addition. The increment of hydrazine concentration also decreases the mass deposited by EPD, as expected from the reduction of the zeta potential absolute value and the electrophoretic mobility of the TiN nanoparticles. Modification of the stabilization state also affects to the homogeneity of the coatings. Considering 

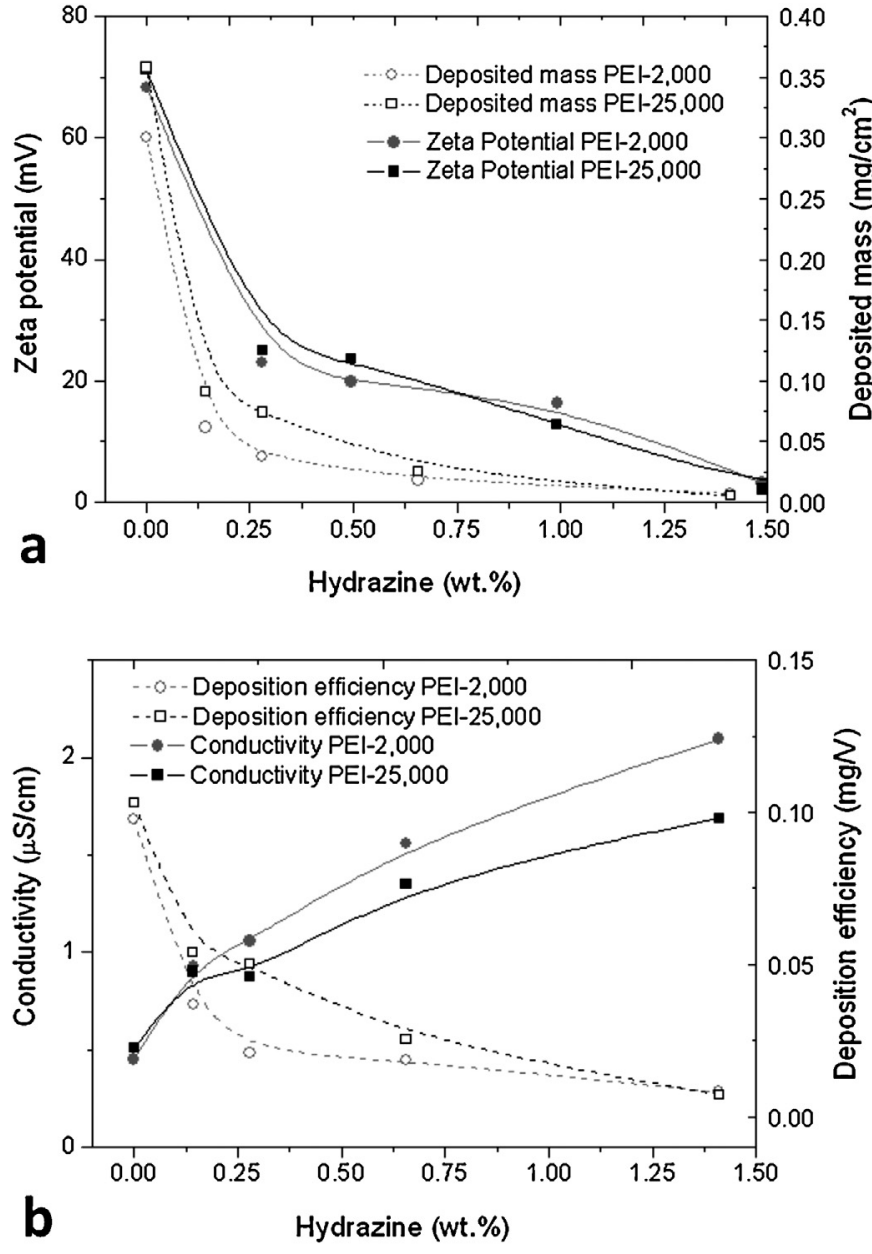

Fig. 2. (a) Evolution of zeta potential and deposited mass by EPD with addition of hydrazine. (b) Evolution of conductivity and deposition efficiency with the addition of hydrazine.

the best conditions to obtain homogeneous coatings, two different contents of hydrazine were selected for each PEI. The addition of $0.28 \mathrm{wt} . \%(0.09 \mathrm{ml})$ and $0.66 \mathrm{wt} . \%(0.22 \mathrm{ml})$ of hydrazine for PEI2,000 and the PEI-25,000 suspensions, respectively, associated with the thinner but still homogeneous coating for each system.

However, the inspection of the evolution of the suspension conductivity and the deposition efficiency in deposited mass per applied volt (Fig. 2b) gives a new perspective to the effect of hydrazine over the EPD success. In general, the addition of hydrazine increases the conductivity (from 0.5 to $2.0 \mu \mathrm{Scm}^{-1}$ ) of the nano-TiN suspension in isopropanol, but this increment of conductivity is slightly higher in the case of TiN particles stabilized by PEI-2,000 adsorption (conductivity increases up to $1.5 \mu \mathrm{Scm}^{-1}$ ). When $1.3 \mathrm{wt}$.\% of hydrazine is added to the suspensions stabilized with 1.5 wt.\% of PEI-2,000 and PEI-25,000, a similar $\mathrm{pH}$ value of 8 is achieved and consequently the protonation state of both chains should be similar. However conductivity is not the same. The PEI2,000 chain was less neutralized than the PEI-25,000 for the same amount of hydrazine. This effect verified the multi-point anchoring of PEI-25,000 in contrast with the single-point adsorption of PEI2,000 . The single-point adsorption leads to a higher amount of free functional groups, and consequently a higher conductivity value. On the other hand, differences in deposition were observed when the deposition efficiency is considered. The stabilization with PEI25,000 results in a higher ratio of mass of TiN deposited per applied volt. From this point of view, regarding the plot in Fig. $2 \mathrm{~b}$ and choosing the addition of $0.28 \mathrm{wt} . \%$ and $0.66 \mathrm{wt} . \%$ of hydrazine for
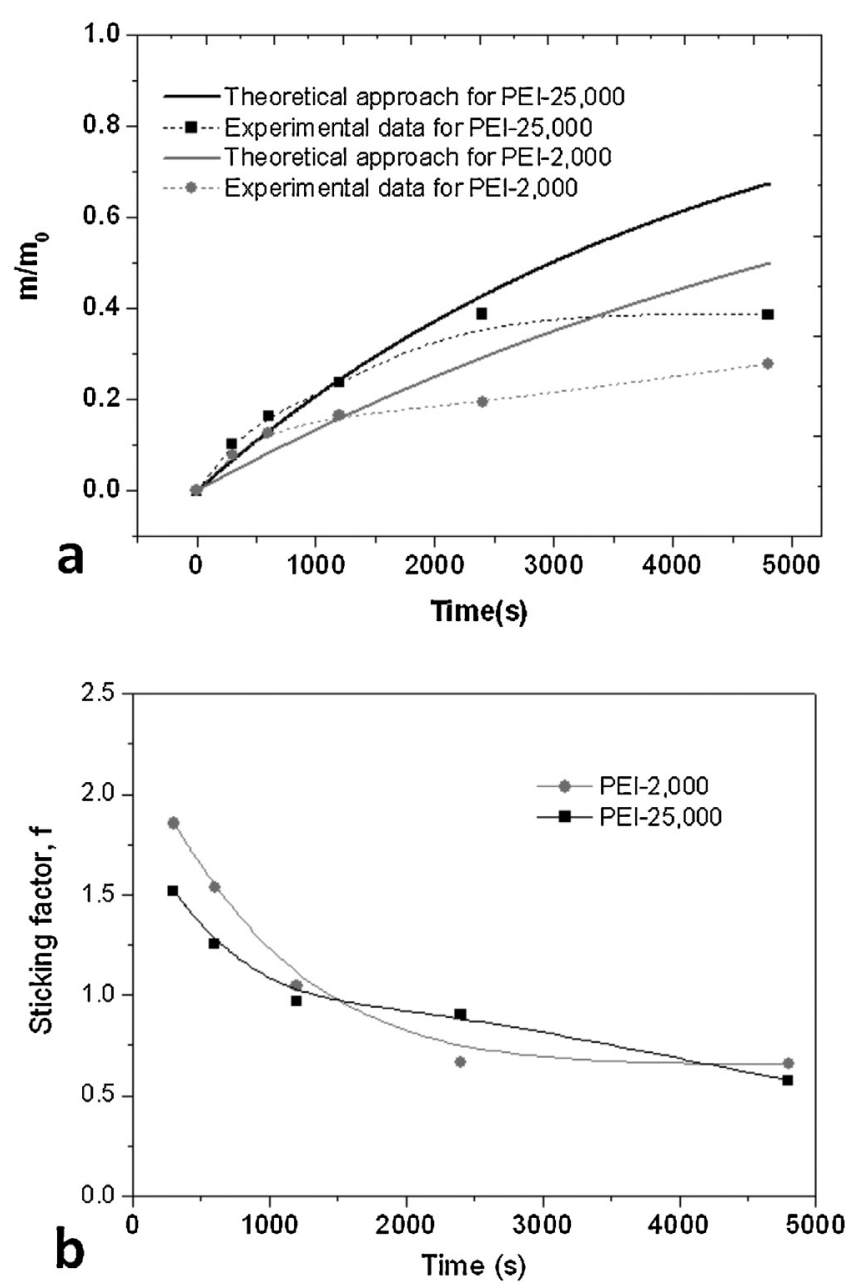

Fig. 3. (a) EPD Kinetics for PEI 2000 and PEI 25,000 including the calculated theoretical kinetics and experimental data. (b) Evolution of the sticking factor for both suspensions.

Table 1

Main EPD parameters describing the boundary conditions of the tests.

\begin{tabular}{lll}
\hline EPD parameters & PEI-2000 & PEI-25,000 \\
Volume of suspension, $V$ & $30 \mathrm{ml}$ & \\
Electrophoretic mobility, & $\mu_{\mathrm{e}} 0.1198 \times 10^{-4} \mathrm{~cm}^{2} \mathrm{~V}^{-1} \mathrm{~s}^{-1} 0.194 \times 10^{-4} \mathrm{~cm}^{2} \mathrm{~V}^{-1} \mathrm{~s}^{-1}$ \\
Deposition surface, $S$ & $8 \mathrm{~cm}^{2}$ & \\
Electric field, $E$ & $45 \mathrm{~V} / \mathrm{cm}$ & \\
Sticking factor, $f$ & 1 & $4295 \mathrm{~s}$ \\
Characteristic time, $T$ & $6956 \mathrm{~s}$ & \\
\hline
\end{tabular}

the PEI-2,000 and the PEI-25,000 suspensions, respectively, thinner and homogeneous TiN coatings were obtained under similar conditions of efficiency for both systems.

The TiN suspensions stabilized adding $1.5 \mathrm{wt} . \%$ of PEI-2,000 and PEI-25,000, and 0.28 wt.\% and 0.66 wt.\% of hydrazine, respectively, were used to study the kinetics of the EPD process. The TiN coatings were shaped by EPD on stainless steel substrates, applying an electric field of $45 \mathrm{~V}$ for times up to $4800 \mathrm{~s}$ ( $80 \mathrm{~min}$ ). EPD tests were performed under potential conditions in order to neglect differences in conductivity between formulated suspensions. During the test the current densities varied between $0.06-0.08 \mathrm{~mA} \mathrm{~cm}^{-2}$ for suspensions stabilized with PEI-2,000 and 0.28 wt.\% of hydrazine, and $0.1-0.2 \mathrm{~mA} \mathrm{~cm}^{-2}$ for suspensions stabilized with PEI-25,000 and 0.66 wt.\% of hydrazine. Fig. 3 shows the theoretical approach calculated with a sticking factor of 1 and the experimental data of deposited mass obtained from suspensions with 0.28 and $0.66 \mathrm{wt} . \%$ of hydrazine for PEI 2000 and PEI 25,000, respectively. Table 1 
Total Energy Interaction : $V_{T}=V_{A}+V_{R}$

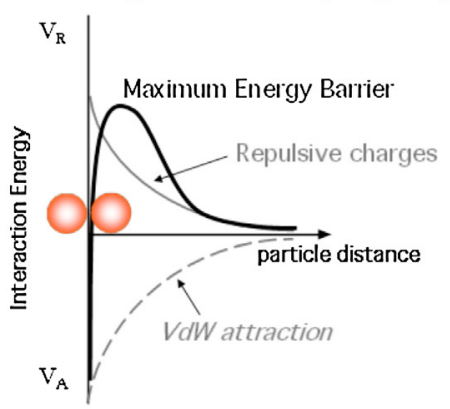

In highly Electro-Static dispersed systems particles need to Flocculate $\left(V_{A}>V_{p}\right)$ at the electrode overpassing a extraordinarily high Energy Barrier

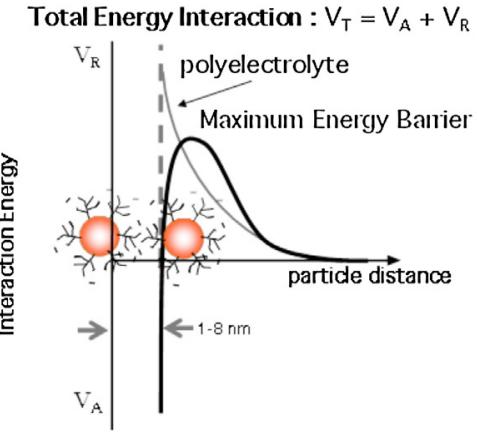

In highly Electro-Steric dispersed systems particles need to Coagulate $\left(V_{A}>V_{B}\right)$ at the electrode overpassing a extraordinarily high Energy Barrier
Total Energy Interaction : $V_{T}=V_{A}+V_{R}$

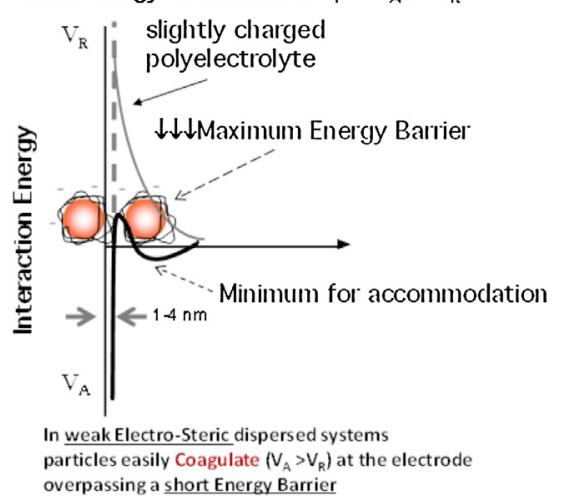

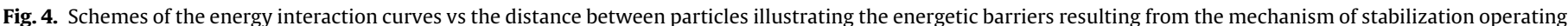
in the suspension.

summarized the values of main EPD parameters which describes the conditions of the tests. These values were used to calculate the theoretical curve of the kinetics of the process for both suspensions. Parameters are the volume of the suspension $(V)$, the electrophoretic mobility $\left(\mu_{\mathrm{e}}\right)$, the deposition surface $(S)$, the electric field $(E)$ and the sticking factor $(f)$. Based on these parameters, the characteristic time of the kinetics for each suspension are $6956 \mathrm{~s}$ and 4295 s for PEI-2,000 and PEI-25,000, respectively. The lower is the characteristic time the faster is the EPD process. So, as expected from the electrophoretic mobility values, theoretically the kinetics of the suspension dispersed by the addition of PEI-25,000 is faster than that of the suspension with PEI-2,000 (under normalized conductivity conditions).

From experimental data, higher deposited mass rates were achieved with the PEI 25,000 suspension even when the concentration of hydrazine is higher. Faster particles provide a faster coating growth. In addition the plot shows that the experimental data are over the theoretical curve for low deposition times. Analyzing the characteristic deposition time of each suspension, it is possible to solve the kinetics equation quantifying the values of the sticking factor, shown at the plot in Fig. 3b. Sticking factor $(f)$ is over 1 for deposition times $<1500 \mathrm{~s}$, and decreases for higher deposition times for both suspensions.

The first consequence derived from the evolution of the sticking factor is that as-formulated suspensions will never provide a $100 \%$ deposition yield. After $1500 \mathrm{~s}$ ( $20 \mathrm{~min}$ ) of deposition time, the stability of the system decreases and deposition process is practicality arrested. The second characteristic of the EPD kinetics of nano-TiN suspensions is the markedly high sticking factor. When the sticking factors vary between $1.5-1.8$ the TiN coatings are $50-80 \%$ heavier than expected.

Contrarily to the Hamaker equation [14], at present electrophoretic models specifically consider changes of parameters during deposition time. These parameters are mainly involved in the electrophoretic behavior of the particles. Although theoretic and experimental studies lead to a clear dependence between suspension parameters and electrical conditions, only the model proposed by Ferrari et al. [14] considers the interdependence of both of them, the solid content of the suspension and its resistivity. However, all these models do not quantify the phenomena taking place at the interface soli-liquid-solid during deposition, and kinetics equations only are represented by one variable: the sticking factor, $f$.

To stablish the relationship between the evolution of the sticking factor and the conditions of the stability of the nanoparticles suspension, it is necessary to standardize other EPD variables. In this work, electrical conditions and some fixed stability conditions contribute to normalize the EPD test, isolating phenomena related to nanoparticles packing at the electrode. In our EPD tests the conductivity of the suspension was reduced as much as possible in order to diminish the effect of secondary reactions at the workelectrode (current transients, overpotentials, etc.) [19]. Moreover, a planar geometry was fixed, as well as polished substrates were used to identify the geometric area with the conductive surface area. Polished substrates also allows considering surface roughness of the electrode, $\mathrm{R}(\mathrm{nm})$, in the same order than the particle diameter, $\mathrm{d}(\mathrm{nm})$, and then the conductive surface area coincides with the deposition surface area [38].

Under fixed conditions, the deposition and particles packing exclusively depend on the colloidal chemistry of the suspension. Modelling of inter-particle forces supposes that the net force acting among particles is an algebraic sum of repulsive and attractive forces [38]. Suspensions currently used in EPD are stabilized throughout an electro-steric mechanism, because of electrophoresis is based in the movement of the particles in a liquid medium by the effect of an electric filed. However, it is demonstrated that this kind of stabilization is not the optimum for packing $[35,39,40]$ especially for nanoparticles. The formation of an extremely wide volume of exclusion surrounding nanoparticles provided by highly ionized polymers, as well as a high potential barrier which difficult the particles approaching [15], decreases the degree of packing when bulk parts or coatings are shaped. In those cases, the decrease of the electrostatic contribution to the electro-steric mechanism of stability could promote a better packing and step up the kinetics of the film growth.

In our suspensions stabilized by the adsorption of PEI on the particles surface, the addition of hydrazine promotes changes on the ionization state of PEI and consequently in the conformation of PEI chains on the particle surface $[39,40]$. PEI changes from "tail" to "train" conformation, especially PEI-25,000 which adsorbs in a multi-point way. Zeta potential measurements in Figs. $1 \mathrm{~b}$ and 2 a evidence the screening of electrostatic interaction forces acting among particles when there are stabilized within the liquid media. Our systems exhibit a mainly steric stabilization which reduces the exclusion volume and the electrostatic potential barrier when particles approach during deposition. Nanoparticles packing was then favored by the own stabilization system, and this could be the reason of the anomalous high sticking factor exhibited by these systems. On the other hand, the sticking factor is higher for PEI2,000 as well as kinetic is faster for PEI-25,000. Both facts are also the consequence of slight differences of stabilization. The TiN nanoparticles stabilized by the addition of PEI-25,000 have a higher electrophoretic mobility so they move faster, but they also exhibit a higher electrostatic interaction and then particles pack slower. 

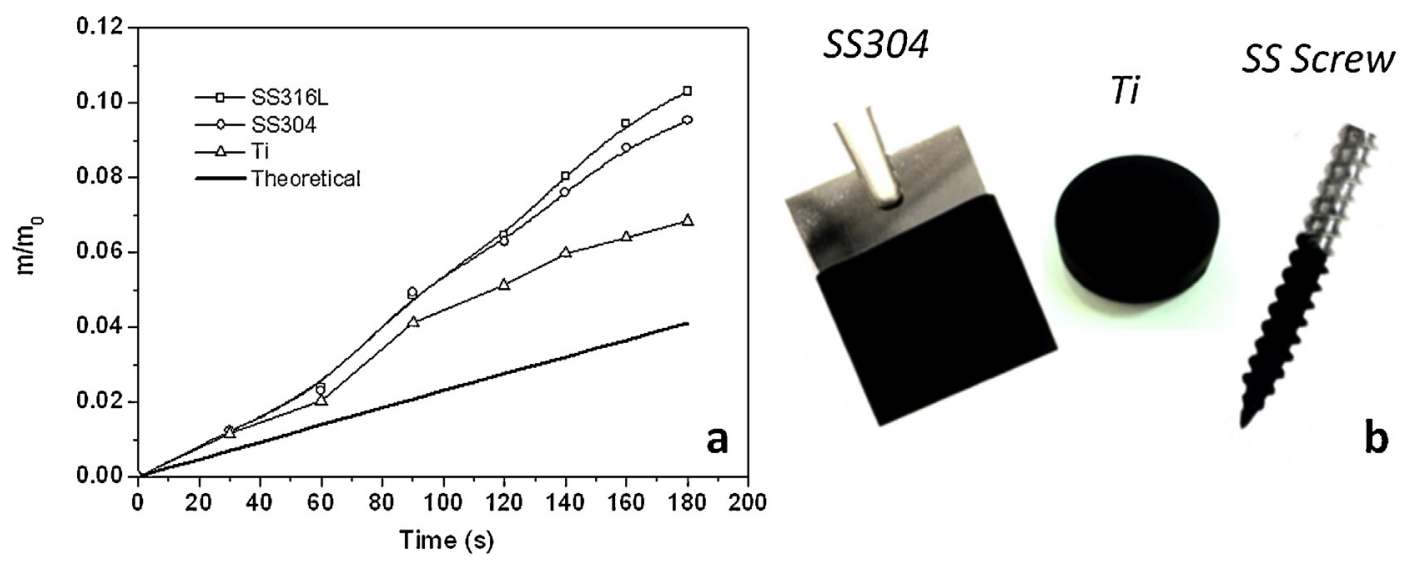

C

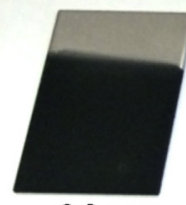

$30 \mathrm{~s}$

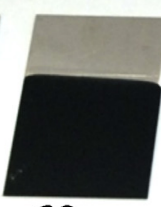

$60 \mathrm{~s}$

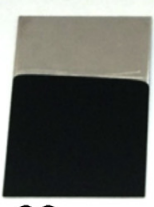

$90 \mathrm{~s}$

\section{SS304}

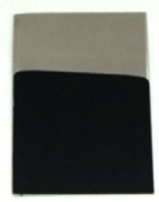

$120 \mathrm{~s}$

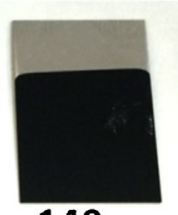

$140 \mathrm{~s}$

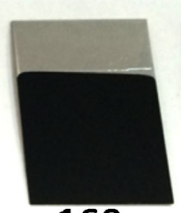

$160 \mathrm{~s}$

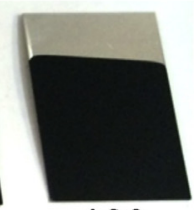

$180 \mathrm{~s}$

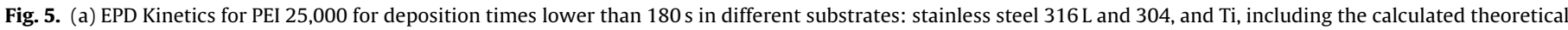
kinetics. (b) Pictures of coatings shaped on stainless steel 304, Ti and a screw. (c) Pictures of TiN coatings shaped by EPD in stainless steel 304.

Fig. 4 shows different schemes of the energy interaction curves vs the distance between surfaces which illustrate the energetic barriers that particles should overpass to adhere and form a cohesive coating on the substrate as a function of the mechanism of stabilization operating in the suspension. The curves of potential energies which determine the interaction among particles can be approximated as a function of the conditions for stabilization (particle size, length of polymer chain, ionic concentration, pH, etc.) [41]. Both electrophoretic mobility and potential energy are key parameters to determine the sticking factor.

The TiN nanoparticles suspension was stabilized by adding 1.5 wt.\% of PEI-25,000 and $0.66 \mathrm{wt} . \%$ of hydrazine $(0.22 \mathrm{ml})$, and tested over different surfaces. Fig. 5a shows the kinetics of nano-TiN deposition for times lower than $180 \mathrm{~s}$ ( 3 min) when using stain-
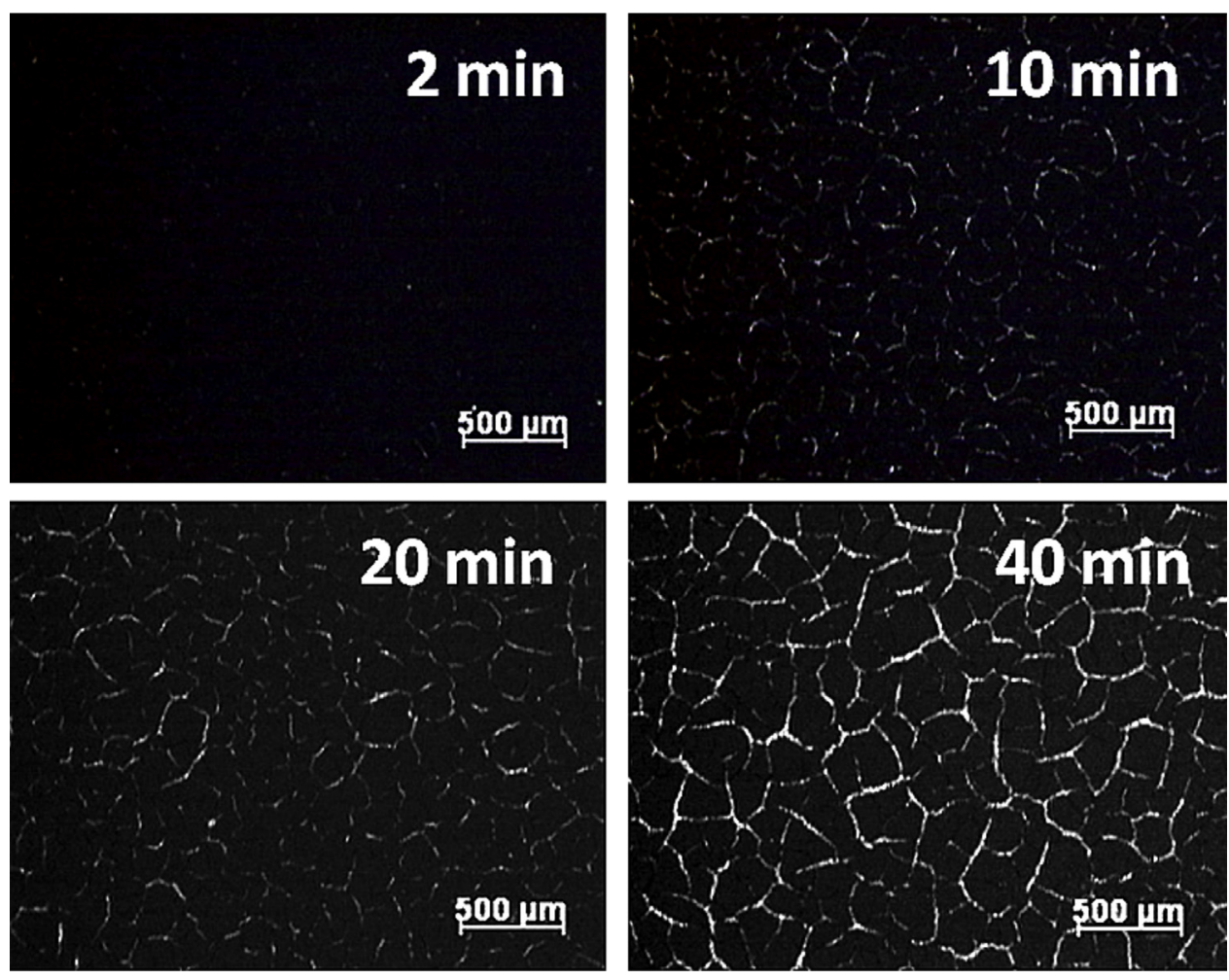

Fig. 6. Pictures of TiN coatings shaped from the suspension stabilized by PEI-25,000 with the addition of 0.66 wt.\% of hydrazine. 

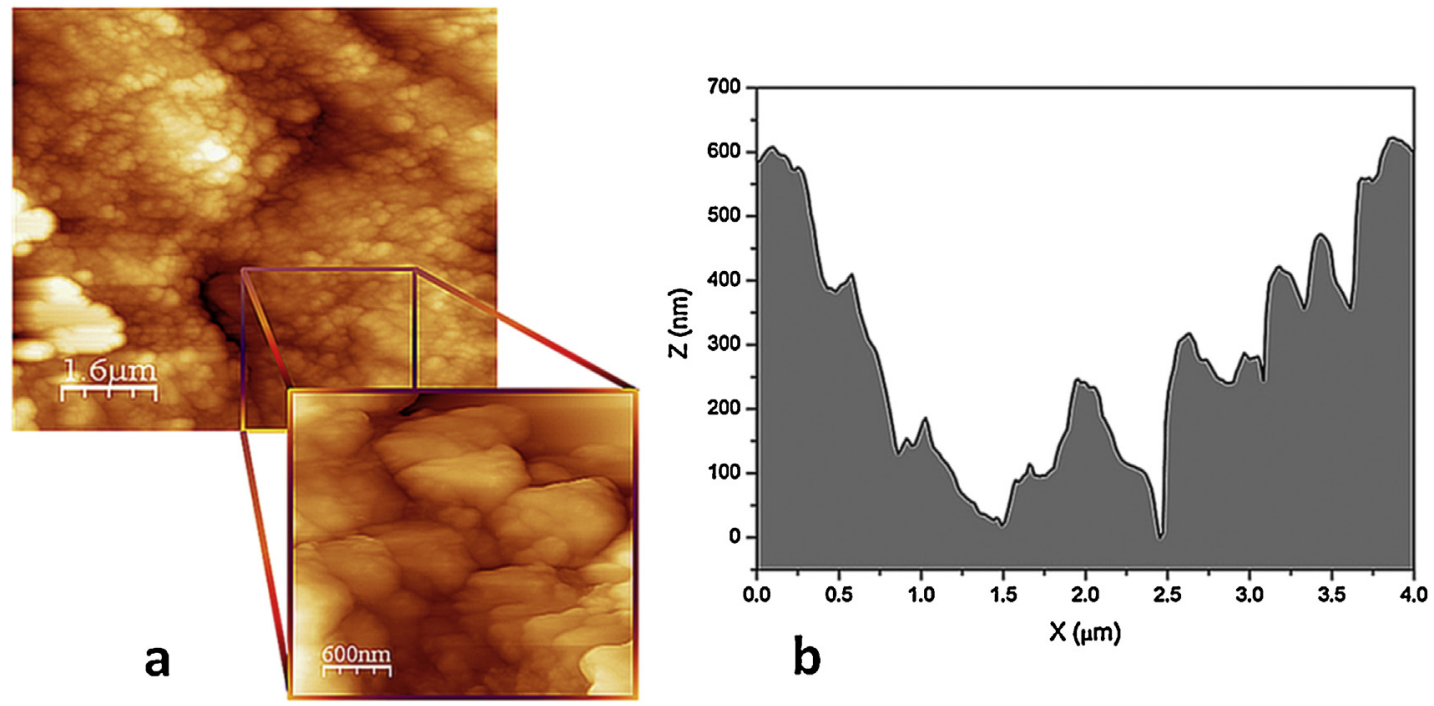

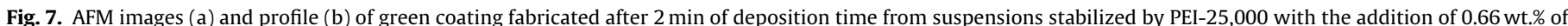
hydrazine.(For interpretation of the references to color in this figure legend, the reader is referred to the web version of this article.)

less steel AISI 316L (SS316L) and AISI304 (SS304) substrates and Ti substrates fabricated by pulvimetallurgy (PM) techniques [42]. Stainless steel surfaces are polished while Ti substrates have an asprepared surface. The TiN coatings are showed in Fig. 5b together with a screw coated. Fig. 5a also shows the calculated theoretical behavior as a reference. All kinetics exhibits a sticking factor higher than 1. Deposition kinetics on stainless steels is quite similar, because of they have similar surface roughness and the differ-
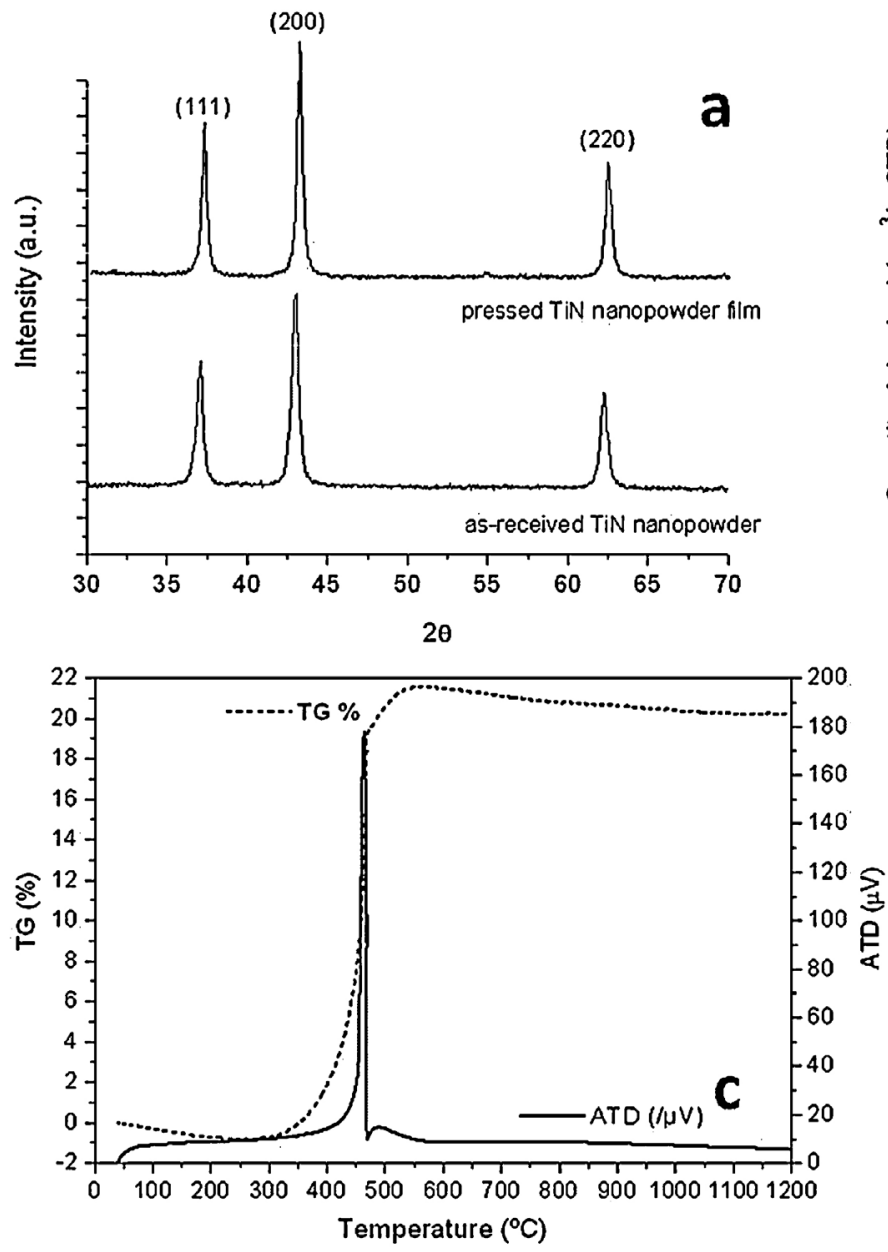
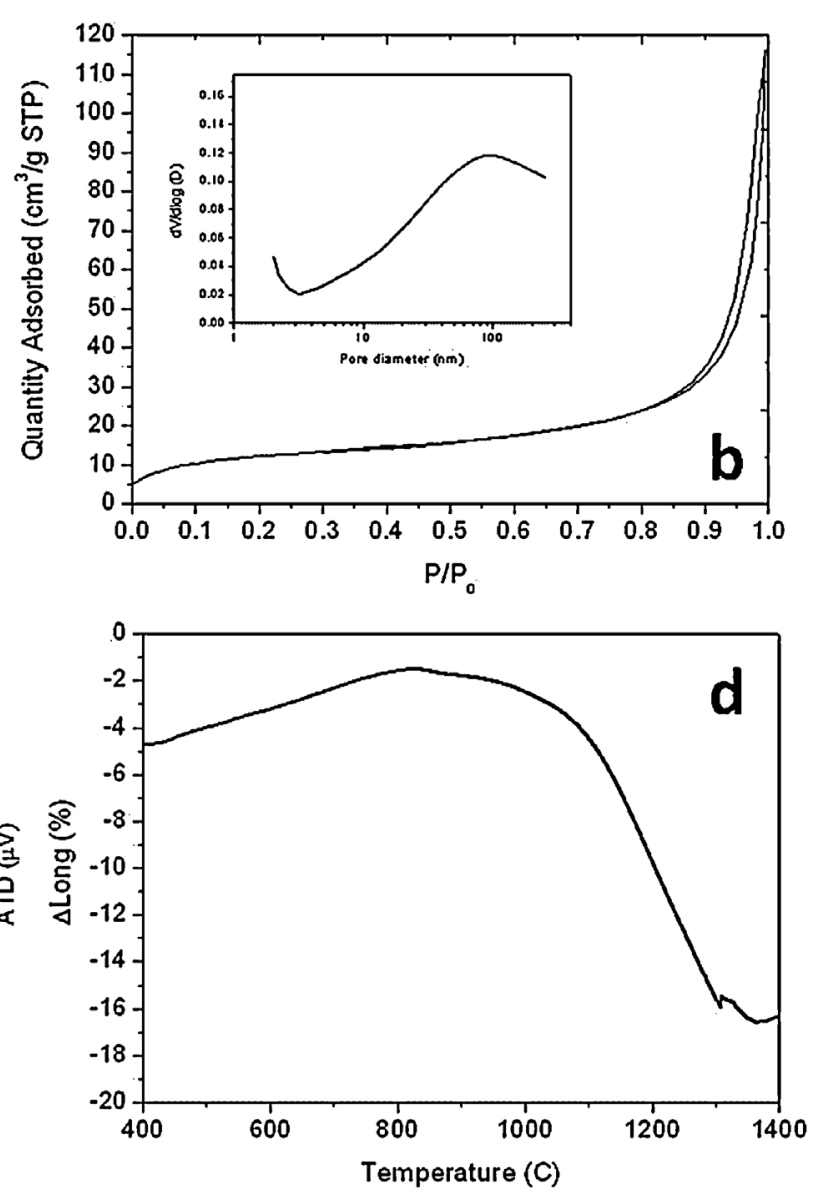

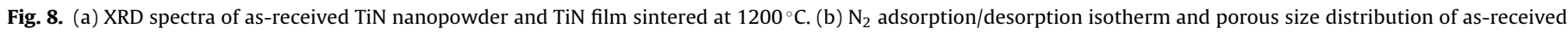
TiN nanopowder. (c) ATD-TG analysis of the as-received TiN nanopowder. (d) Dilatometry of TiN film obtained by uniaxial pressing of TiN nanopowder. 

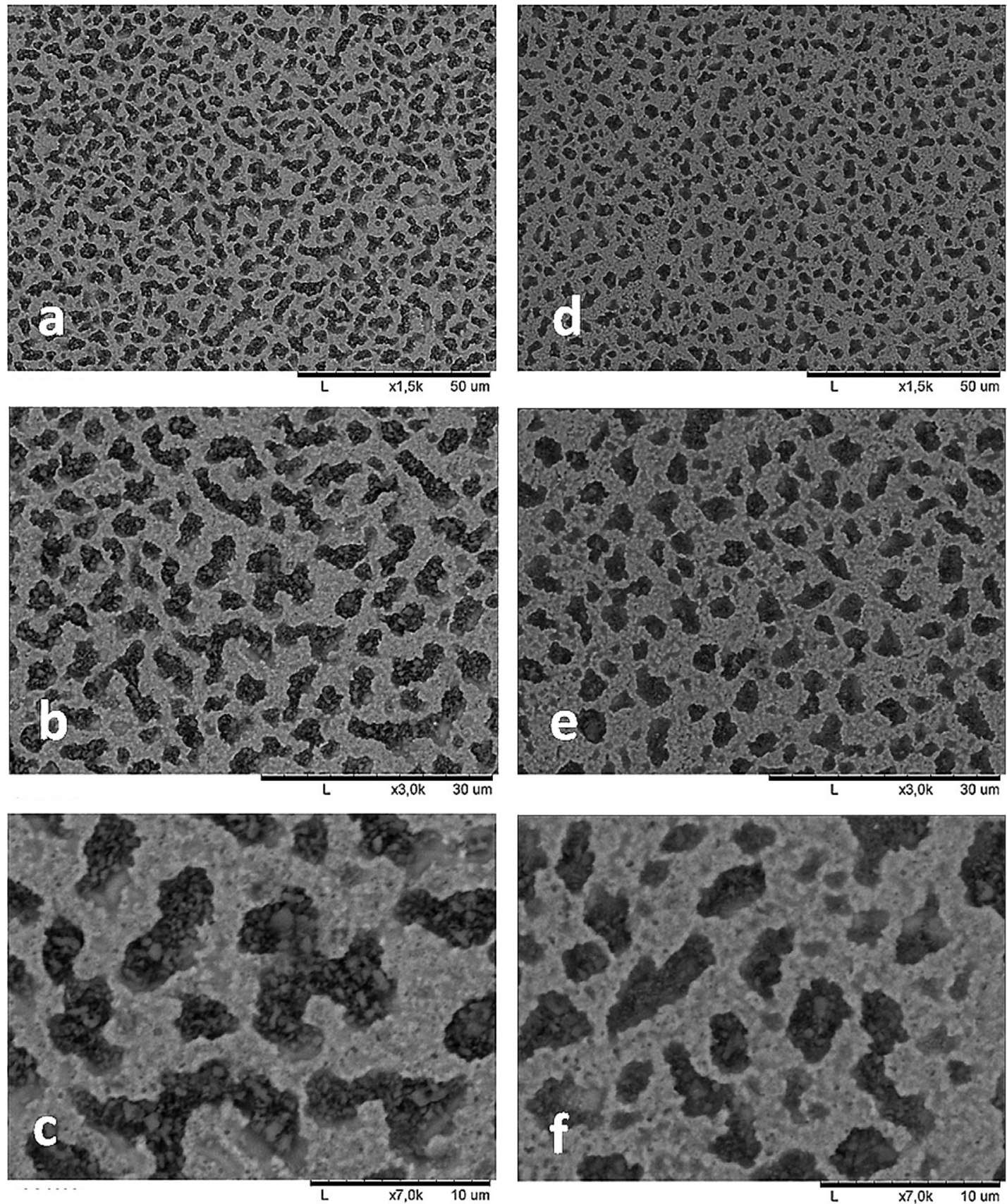

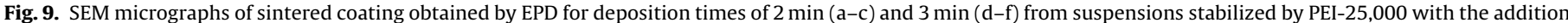
of 0.66 wt.\% of hydrazine at different magnifications.

ences in the metal conductivity are negligible in EPD [43]. The coatings fabricated by EPD cover evenly the AISI surfaces (picture in Fig. 5c). However, deposition kinetics in as-prepared Ti is slower than in polished work electrodes. The decrease of the deposition rate could be associated to the higher roughness (maximum roughness around $13 \mu \mathrm{m}$ ) and to the $2 \%$ closed porosity randomly distributed at the surface of this kind of PM substrates. However, the uniform distribution of TiN nanoparticles on the as-prepared Ti surface is not affected by the lower deposition rate as shown at the picture in Fig. 5b. Finally, the optimization of the stability of TiN suspension and the parameters of the EPD performance allows covering complex shapes as the screw shown at the picture in Fig. 5b.

An important aspect during the EPD process is associated to avoid the cracking of the ceramic coating during drying [44]. Dur- ing this process, the evaporation of the solvents occurs together with the densification, and the shrinkage of the coatings, but dense substrates do not change on dimensions. The coating will develop tensile stress and these stresses will release throughout cracks growth. In this system we use an organic solvent which increases the drying rate at room conditions stepping up cracking. Fig. 6 shows the optical micrographs of TiN coatings on stainless steel 304 as a function of deposition time. The fabrication of crack-free films requires low deposition times, $<5 \mathrm{~min}$.

It is important to describe the surface networks developed during particle clustering, which is critical for predicting particle arrangement at the nanoscale. In this sense, the use of AFM to the study of particle sticking and packing is a helpful tool. In Fig. 7, AFM images show the compacted surface of TiN coating obtained by EPD for a deposition time of $2 \mathrm{~min}$. The TiN coating displays a dense and 

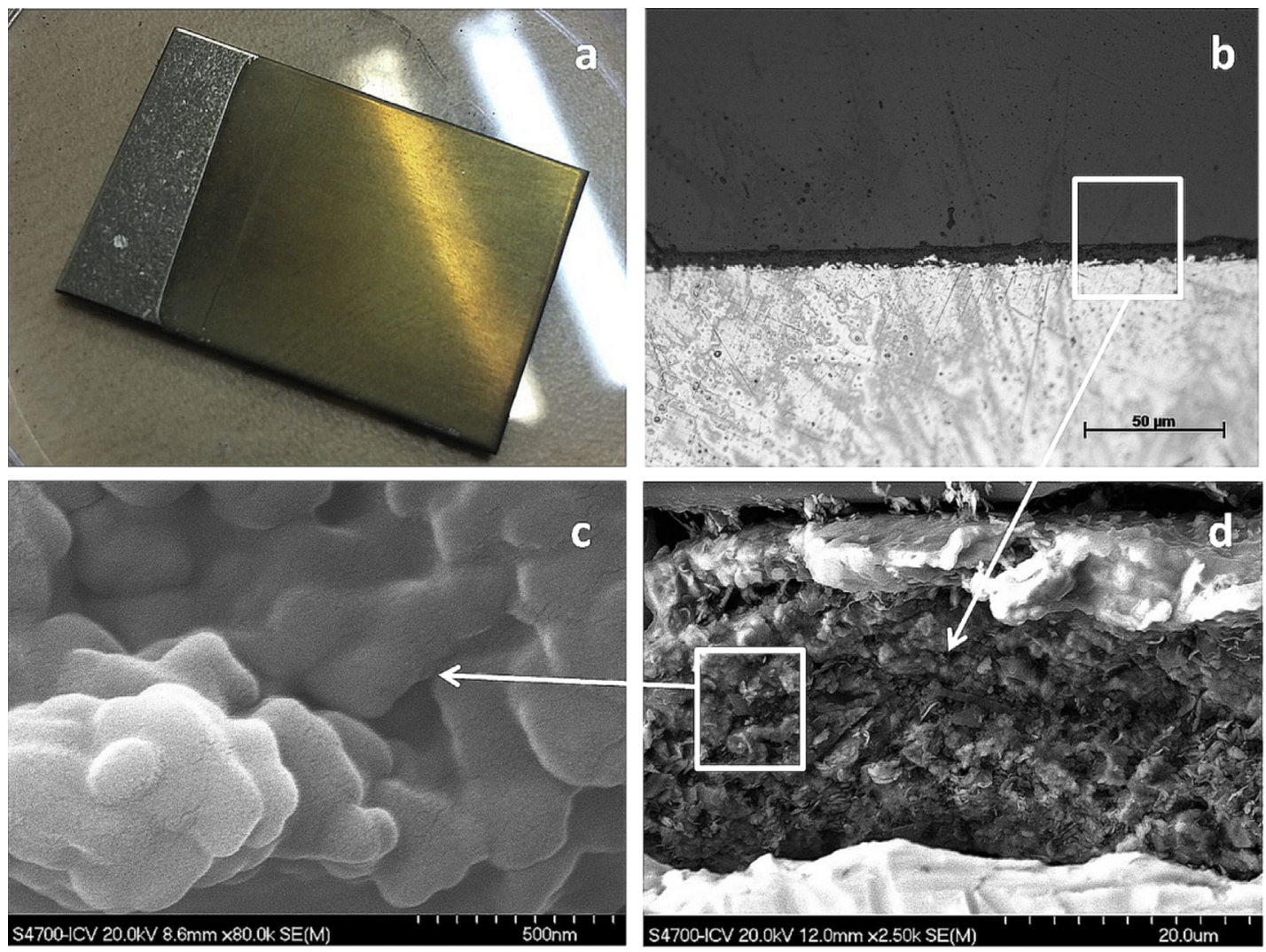

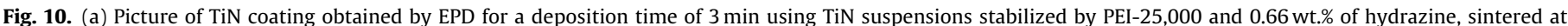
$1200^{\circ} \mathrm{C}$ during $1 \mathrm{~h}$ in vacuum atmosphere. (b) ORLM image and (c and d) FE-SEM images at different magnifications of TiN consolidated coating.

high particles packing degree. A detail of the topography shows TiN agglomerates of $200 \mathrm{~nm}$ in size, while the profile of the nanostructure exhibits a roughness equivalent to three times the diameter of TiN agglomerates. So, the TiN agglomerates are the building blocks of the TiN coating which confirms that agglomerates in the micrographs (Fig. 1a) are aggregates produced during the preparation of commercial powders.

\subsection{Characterization of the sintered TiN coatings}

Fig. 8 shows the results of the morphological and the thermal analysis of as-received TiN nanopowder. Plot in Fig. 8 shows the X-ray diffraction (XRD) pattern of as-received TiN nanopowder. The diffraction pattern indicates the presence of a crystalline phase with three characteristic peaks $\left(37.25^{\circ}, 43.20^{\circ}\right.$ and $\left.62.43^{\circ}\right)$ corresponding to (111), (200) and (220) planes of cubic TiN (JCPDS 00-38-1420). Fig. 8b shows the $\mathrm{N}_{2}$ adsorption/desorption isotherms and the pore size distribution of the as-received TiN nanopowders. The shape of the isotherm indicates the low amount of micro and mesopores of TiN nanoparticles. The low adsorbed volume at very low relative pressure $(P / P o<0.01)$ verifies the presence of low amount of micropores ( $<3 \mathrm{~nm}$ in the pore size distribution at the inset). The type II nitrogen isotherm and the narrow hysteresis at high relative pressure evidences the presence of fine macropores with pore sizes $>50 \mathrm{~nm}$ (pore size distribution at the inset). The TiN nanopowders have a specific surface area of $44.42 \mathrm{~m}^{2} \mathrm{~g}^{-1}$ and a density of $3.27 \mathrm{~g} \mathrm{~cm}^{-3}$. Values of the specific surface area and low density (theoretical density of TiN is $5.22 \mathrm{~g} \mathrm{~cm}^{-3}$ ), as well as the adsorption/desorption isotherms, evidence the open and smooth structure of the TiN nanoparticles (26-32 nm) or the aggregates/agglomerates of $200 \mathrm{~nm}$ (Fig. 1a).
TG-DTA analysis in Fig. 8c exhibits a marked exothermic peak at $460^{\circ} \mathrm{C}$ associated to a $25 \%$ gain of weight. The gain of weight, and the related exothermic peak, indicates the partial oxidation in air of asreceived powder above this temperature. Finally, the dilatometry (Fig. 8d) evidences the evolution of a TiN slice, obtained by pressing, during consolidation under $\mathrm{N}_{2}$ atmosphere. The evolution of the TiN film shows the shrinkage up to $500^{\circ} \mathrm{C}$ associated with the smooth structure of the as-received TiN aggregates. Final consolidation of the microstructure is reached at $1200^{\circ} \mathrm{C}$, several hundred degrees below the regular temperatures reported in the literature. The XRD spectrum of the sintered TiN slice was also plotted in Fig. 8a. Diffratogram shows an increment of TiN crystallinity after the thermal treatment at $1200^{\circ} \mathrm{C}$, but also evidence the absence of massive titanium oxide $(<5 \%)$. Warren equation and Scherrer analysis suggests the increase of the crystal size from $25 \mathrm{~nm}$ to $30 \mathrm{~nm}$ after the TiN sinterization.

In view of the thermal characterization of the TiN powders, the heat treatments of TiN coatings obtained after deposition times of 2 and 3 min on AISI $316 \mathrm{~L}$ stainless steel were carried out at $1200^{\circ} \mathrm{C}$ for 1 hour in vacuum in order to consolidate the TiN structure avoiding oxidation [45]. The EPD coatings thermally treated were prepared with the suspension stabilized with PEI-25,000 and the addition of $0.66 \mathrm{wt}$.\% of hydrazine. The surface of these samples was analyzed by SEM (Fig. 9). Consolidated microstructures of TiN films exhibits completely different surfaces as a consequence of the film shrinkage during sintering and the amount of deposited powders. The porosity and the connectivity among pores decrease as deposition time increases. That means, longer deposition times result in higher deposited mass (Fig. 5a) but also in a well compacted structure of particles. The higher packing degree of TiN films obtained after 3 min of EPD leads to a well consolidated structure with a lower amount of porous after the thermal treatment. 
The inspection of these microstructures at a higher magnification (Fig. 9c, 9f and later in Fig. 10d) evidences the neck formation among particles, but not a full microstructure consolidation. On the other hand, a basal TiN film can be intuited through the porosity. The thickness was measured and the adhesion was evaluated in the cross section using an optical microscope and FE-SEM (Fig. 10) for well compacted deposits obtained after 3 min of deposition time. A highly homogeneous coating with thickness around $10-20 \mu \mathrm{m}$ is observed (Fig. 10b-d). At the film picture in Fig. 10a, the coating has the golden feature of sintered TiN. A deep inspection of the micrographs confirms the advanced state of consolidation of the TiN film microstructure, although aggregates of $200 \mathrm{~nm}$ and TiN nanoparticles of $20-40 \mathrm{~nm}$ can be intuited at the detail of the microstructure in Fig. 10d.

\section{Conclusions}

TiN coatings sintered at a temperature as low as at $1200^{\circ} \mathrm{C}(1 \mathrm{~h}$ in vacuum atmosphere), have been shaped by EPD. Suspensions of TiN nanoparticles prepared to fabricate homogenous coatings were firstly stabilized through electro-steric mechanism by adding 1.5 wt.\% of PEI with two different molecular weights. The electrostatic contribution of the PEI adsorbed on the surface of TiN nanoparticles was masked by the addition of hydrazine and thus, the provided mechanism of stabilization is predominantly steric. Under these conditions of stabilization, the EPD kinetics steps up while nanoparticles packing improve.

The EPD kinetics of TiN suspensions exhibits a sticking factor higher than 1 . The PEI absorbed onto the TiN particles reduces the exclusion volume and the electrostatic potential barrier, favouring the flocculation of the nanoparticles and thus the coating growth. Consequently, experimental results exceed those theoretically calculated. When the process efficiency was fixed, the addition of hydrazine $(0.66 \mathrm{wt} . \%)$ promotes the train conformation of the PEI25,000 (1.5 wt.\%) on the surface of TiN nanoparticles, resulting in a faster electrophoretic movement but a slower particles packing.

The stabilization of suspensions by steric mechanism increases the viability of the process. Similar coatings can be obtained in substrates with different nature, roughness and geometries. TiN covers completely the stainless steel substrate, but also exhibits a highly porous and rough surface, extremely relevant for cell growth in the functionalised surface of implants.

\section{Acknowledgements}

This work has been supported by the Spanish Ministry of Economy and Competitiveness (MINECO) under contract MAT201238650-C02-01 and Community of Madrid (CAM) for MULTIMAT Challenge Project (S2013/MIT-2862). Dr. Zoilo González acknowledges to MINECO through the grant PTQ-13-05985.

\section{References}

[1] S. Rtimi, O. Baghriche, C. Pulgarin, R. Sanjines, J. Kiwi, Design, testing and characterization of innovative $\mathrm{TiN}-\mathrm{TiO}_{2}$ surfaces inactivating bacteria under low intensity visible light, RSC Adv. 2 (2012) 8591

[2] M.-S. Balogun, W. Qiu, W. Wang, P. Fang, X. Lu, Y. Tong, Recent advances in metal nitrides as high-performance electrode materials for energy storage devices, J. Mater. Chem. A 3 (2015) 1364-1387 http://dx.doi.org/10.1039/ C4TA05565A

[3] R. Wei, E. Langa, C. Rincon, J.H. Arps, Deposition of thick nitrides and carbonitrides for sand erosion protection, Surf. Coat. Technol. 201 (2006) 4453-4459 http://dx.doi.org/10.1016/j.surfcoat.2006.08.091

[4] L. Zhang, H. Yang, X. Pang, K. Gao, A.A. Volinsky, Microstructure, residual stress, and fracture of sputtered TiN films, Surf. Coat. Technol. 224 (2013) 120-125 http://dx.doi.org/10.1016/j.surfcoat.2013.03.009

[5] J. Russias, S. Cardinal, Y. Aguni, G. Fantozzi, K. Bienvenu, J. Fontaine, Influence of titanium nitride addition on the microstructure and mechanical properties of TiC-based cermets, Int. J. Refract. Met. Hard Mater. 23 (2005) 358-362 http://dx.doi.org/10.1016/j.ijrmhm.2005.05.008

[6] T.R. Rautray, R. Narayanan, K.H. Kim, Ion implantation of titanium based biomaterials, Prog. Mater. Sci. 56 (2011) 1137-1177 http://dx.doi.org/10. 1016/j.pmatsci.2011.03.002

[7] S.V. Fortuna, Y.P. Sharkeev, A.J. Perry, J.N. Matossian, I.A. Shulepov, Microstructural features of wear-resistant titanium nitride coatings deposited by different methods, Thin Solid Films 377-378 (2000) 512-517 http://dx.doi. org/10.1016/S0040-6090(00)1,438-3

[8] L. Dobrzañski a, K. Golombek, Structure and properties of selected cemented carbides and cermets covered with $\mathrm{TiN} /(\mathrm{Ti}, \mathrm{Al}, \mathrm{Si}) \mathrm{N} / \mathrm{TiN}$ coatings obtained by the cathodic arc evaporation process, Mater. Res. 8 (2005) 113-116 http://dx. doi.org/10.1590/S1516-14392005000200002

[9] V.A.R. Henriques, C.A.A. Cairo, E.T. Galvani, Development of titanium nitride coatings in titanium alloys by electron beam physical vapor deposition, 2008 , http://dx.doi.org/10.4271/2008-36-0016

[10] M. Burke, A. Blake, I.M. Povey, M. Schmidt, N. Petkov, P. Carolan, et al., Low sheet resistance titanium nitride films by low-temperature plasma-enhanced atomic layer deposition using design of experiments methodology, J.Vac. Sci. Technol. Vacuum Surf. Film 32 (2014) 031506.

[11] M.A.M. Ibrahim, F. Kooli, S.N. Alamri, Electrodeposition and characterization of nickel-TiN microcomposite coatings, Int. J. Electrochem. Sci. 8 (2013) 12308-12320.

[12] S. Kaskel, K. Schlichte, G. Chaplais, M. Khanna, Synthesis and characterisation of titanium nitride based nanoparticles, J. Mater. Chem. 13 (2003) 1496 http://dx.doi.org/10.1039/b209685d

[13] C. Giordano, M. Antonietti, Synthesis of crystalline metal nitride and metal carbide nanostructures by sol-gel chemistry, Nano Today 6 (2011) 366-380 http://dx.doi.org/10.1016/j.nantod.2011.06.002

[14] B. Ferrari, R. Moreno, EPD kinetics: a review, J. Eur. Ceram. Soc. 30 (2010) 1069-1078 http://dx.doi.org/10.1016/j.jeurceramsoc.2009.08.022

[15] P. Sarkar, P.S. Nicholson, Electrophoretic deposition (EPD): mechanisms, kinetics, and application to ceramics, J. Am. Ceram. Soc. 79 (1996) 1987-2002 http://dx.doi.org/10.1111/j

[16] S.-K. Rha, T.P. Chou, G. Cao, Y.-S. Lee, W.-J. Lee, Characteristics of silicon oxide thin films prepared by sol electrophoretic deposition method using tetraethylorthosilicate as the precursor, Curr. Appl. Phys. 9 (2009) 551-555 http://dx.doi.org/10.1016/j.cap.2008.03.023

[17] R. Riahifar, E. Marzbanrad, B.R. Dehkordi, C. Zamani, Role of substrate potential on filling the gap between two planar parallel electrodes in electrophoretic deposition, Mater. Lett. 64 (2010) 559-561 http://dx.doi.org/ 10.1016/j.matlet.2009.11.031

[18] J.J. Van Tassel, C.A. Randall, Ionic gradients at an electrode above the equilibrium limit current. 2. Transition to convection, J. Phys. Chem. C 111 (2007) 3349-3357 http://dx.doi.org/10.1021/jp064805q

[19] C. Baldisserri, D. Gardini, C. Galassi, An analysis of current transients during electrophoretic deposition (EPD) from colloidal $\mathrm{TiO}_{2}$ suspensions, J. Colloid Interface Sci. 347 (2010) 102-111 http://dx.doi.org/10.1016/j.jcis.2010.03.034

[20] Y.S. Joung, C.R. Buie, Electrophoretic deposition of unstable colloidal suspensions for superhydrophobic surfaces, Langmuir 27 (2011) 4156-4163 http://dx.doi.org/10.1021/la200286t

[21] M. Farrokhi-Rad, M. Ghorbani, Stability of titania nano-particles in different alcohols, Ceram. Int. 38 (2012) 3893-3900 http://dx.doi.org/10.1016/j. ceramint.2012.01.041

[22] J. Cihlar, D. Drdlik, Z. Cihlarova, H. Hadraba, Effect of acids and bases on electrophoretic deposition of alumina and zirconia particles in 2-propanol, J. Eur. Ceram. Soc. 33 (2013) 1885-1892 http://dx.doi.org/10.1016/j. jeurceramsoc.2013.02.017

[23] F. Guo, I.P. Shapiro, P. Xiao, Effect of $\mathrm{HCl}$ on electrophoretic deposition of yttria stabilized zirconia particles in organic solvents, J. Eur. Ceram. Soc. 31 (2011) 2505-2511 http://dx.doi.org/10.1016/j.jeurceramsoc.2011.02.027

[24] H. Xu, I.P. Shapiro, P. Xiao, The influence of $\mathrm{pH}$ on particle packing in YSZ coatings electrophoretically deposited from a non-aqueous suspension, J. Eur. Ceram. Soc. 30 (2010) 1105-1114 http://dx.doi.org/10.1016/j.jeurceramsoc. 2009.07.021

[25] C. Ponzoni, M. Cannio, R. Rosa, C. Leonelli, Stabilization of bismuth ferrite suspensions in aqueous medium with sodium polyacrylate characterized by different molecular weights, Mater. Chem. Phys. 149-150 (2015) 246-253 http://dx.doi.org/10.1016/j.matchemphys.2014.10.013

[26] M. Navidirad, B. Raissi, R. Riahifar, M.S. Yaghmaee, A. Kazemzadeh, Effect of polyethylenimine on electrophoretic deposition of $\mathrm{TiO}_{2}$ nanoparticles in alternating current electric field, J. Mater. Sci. Mater. Electron. 25 (2014) 5041-5050 http://dx.doi.org/10.1007/s10854-014-2269-4

[27] J. Esmaeilzadeh, S. Ghashghaie, P.S. Khiabani, A. Hosseinmardi, E. Marzbanrad, B. Raissi, et al., Effect of dispersant on chain formation capability of $\mathrm{TiO}_{2}$ nanoparticles under low frequency electric fields for $\mathrm{NO}_{2}$ gas sensing applications, J. Eur. Ceram. Soc. 34 (2014) 1201-1208 http://dx.doi.org/10. 1016/j.jeurceramsoc.2013.11.022

[28] D. Drdlik, E. Bartonickova, H. Hadraba, J. Cihlar, Influence of anionic stabilization of alumina particles in 2-propanol medium on the electrophoretic deposition and mechanical properties of deposits, J. Eur. Ceram. Soc. 34 (2014) 3365-3371 http://dx.doi.org/10.1016/j.jeurceramsoc. 2014.04.038

[29] H.L. Zhang, J. Li, G.H. Zhou, S.W. Wang, Fabrication of aluminium nitride by electrophoretic deposition, Adv. Mater. Res. 412 (2011) 183-186 http://dx. doi.org/10.4028/www.scientific.net/AMR.412.183 
[30] M. Verde, A.C. Caballero, Y. Iglesias, M. Villegas, B. Ferrari, Electrophoretic deposition of flake-shaped ZnO nanoparticles, J. Electrochem. Soc. 157 (2010) H55 http://dx.doi.org/10.1149/1.3247343

[31] S. Cabanas-Polo, Z. Gonzalez, J.a. Sanchez-Herencia, B. Ferrari, a. Caballero, L. Hernán, et al., Cyclability of binder-free á-Ni(OH) 2 anodes shaped by EPD for Li-ion batteries, J. Eur. Ceram. Soc. 35 (2015) 573-584 http://dx.doi.org/10. 1016/j.jeurceramsoc.2014.08.014

[32] L. Besra, T. Uchikoshi, T.S. Suzuki, Y. Sakka, Experimental verification of pH localization mechanism of particle consolidation at the electrode/solution interface and its application to pulsed DC electrophoretic deposition (EPD), J. Eur. Ceram. Soc. 30 (2010) 1187-1193 http://dx.doi.org/10.1016/j. jeurceramsoc.2009.07.004

[33] M. Mishra, Y. Sakka, T. Uchikoshi, L. Besra, PH localization: a case study during electrophoretic deposition of ternary MAX phase carbide- $\mathrm{Ti}_{3} \mathrm{SiC}_{2}$, Nippon Seramikkusu Kyokai Gakujutsu Ronbunshi/J. Ceram. Soc. Jpn. 121 (2013) 348-354 http://dx.doi.org/10.2109/jcersj2.121.348

[34] L. Dusoulier, R. Cloots, B. Vertruyen, R. Moreno, O. Burgos-Montes, B. Ferrari, $\mathrm{YBa}_{2} \mathrm{Cu}_{3} \mathrm{O}_{7-x}$ dispersion in iodine acetone for electrophoretic deposition: surface charging mechanism in a halogenated organic media, J. Eur. Ceram. Soc. 31 (2011) 1075-1086 http://dx.doi.org/10.1016/j.jeurceramsoc.2011.01. 008

[35] J.A. Escribano, B. Ferrari, P. Alvaredo, E. Gordo, J.A. Sánchez-Herencia, Colloidal processing of Fe-based metalceramic composites with high content of ceramic reinforcement, Boletán Soc. Espaí Cerñmica Vidr. 52 (2014) 247-250 http://dx.doi.org/10.3989/cyv.312013

[36] R.G. Neves, J.A. Escribano, B. Ferrari, E. Gordo, A.J. Sanchez-Herencia, Improvement of Ti processing through colloidal techniques, Key Eng. Mater. 520 (2012) 335-340 http://dx.doi.org/10.4028/www.scientific.net/KEM.520. 335
[37] M. Verde, M. Peiteado, A.C. Caballero, M. Villegas, B. Ferrari, Electrophoretic deposition of transparent $\mathrm{ZnO}$ thin films from highly stabilized colloida suspensions, J. Colloid Interface Sci. 373 (2012) 27-33 http://dx.doi.org/10. 1016/j.jcis.2011.09.039

[38] R. Moreno, B. Ferrari, Electrophoretic Deposition of Nanomaterials, Springer 2012 http://dx.doi.org/10.1007/978-1-4419-9730-2

[39] J.A. Lewis, Colloidal processing of ceramics, J. Am. Ceram. Soc. (2000) 2341-2359 http://dx.doi.org/10.1111/j

[40] W.M. Sigmund, N.S. Bell, L. Bergstrom, Novel powder-processing methods for advanced ceramics, J. Am. Ceram. Soc. 83 (2000) 1557-1574 http://dx.doi.org $10.1111 / \mathrm{j}$

[41] U. Aschauer, O. Burgos-Montes, R. Moreno, P. Bowen, Hamaker 2: a toolkit for the calculation of particleinteractions and suspension stability and its application to mullite synthesis by colloidal methods, J. Dispers. Sci Technol. 32 (2011) 470-479 http://dx.doi.org/10.1080/01932691003756738

[42] R.G. Neves, B. Ferrari, A.J. Sanchez-Herencia, E. Gordo, Colloidal approach for the design of Ti powders sinterable at low temperature, Mater. Lett. 107 (2013) 75-78 http://dx.doi.org/10.1016/j.matlet.2013.05.015

[43] B. Ferrari, R. Moreno, Electrophoretic deposition of aqueous alumina slips, J. Eur. Ceram. Soc. 96 (1997) http://dx.doi.org/10.1016/S0955-2219

[44] P. Sarkar, D. De, H. Rho, Synthesis and microstructural manipulation of ceramics by electrophoretic deposition, J. Mater. Sci. 39 (2004) 819-823 http://dx.doi.org/10.1023/B:JMSC

[45] R.G. Neves, B. Ferrari, A.J. Sanchez-Herencia, C. Pagnoux, E. Gordo, $\mathrm{Ti}-\mathrm{Al}_{2} \mathrm{O}_{3}$ composites processed by pressure slip casting, Powder Technol. 263 (2014) 81-88 http://dx.doi.org/10.1016/j.powtec.2014.04.093 